Vol. 1 No. 1, Maret 2021, hlm. 55 - 64

DOI: $\operatorname{xxxxxxxxxxxxxxxxx}$

Available online at http:// jurnal.stmikroyal.ac.id/index.php/j-com

\title{
SISTEM INFORMASI SURVEI PENYUSUNAN DISAGREGASI PEMBENTUKAN MODAL TETAP BRUTO (PMTB) BERBASIS WEB
}

\author{
Cris Karya Yudha ${ }^{1}$, Virdyra Tasril ${ }^{2 *}$, Randi Rian Putra ${ }^{2}$ \\ ${ }^{1}$ Mahasiswa Prodi Sistem Informasi, Universitas Pembangunan Pancabudi \\ ${ }^{2}$ Prodi Sistem Komputer, Universitas Pembangunan Pancabudi \\ *email:virdyra@dosen.pancabudi.ac.id
}

\begin{abstract}
Susenas is one of the important household socio-economic data sources in Indonesia. Susenas has become the main reference for meeting the needs of the government in implementing national development so that it is in line with the National Medium Term Development Plan (RPJMN), nine priority agendas or nawacita and the goals of Sustainable Development. A survey is a method of collecting data by giving questions to respondents. a survey is the best way to get correct information and the results can be justified. In the process of collecting PMTB survey data, which is carried out by partner officers, it is still implementing a manual system where partner officers come to the company / business under the form to fill in the company's income and expenditure data, and then the partner returns to the ledger to be analyzed by the Balance Sheet officer, the author intends to create a web-based system that is considered to provide an effective solution and can be used as a tool for PMTB data collection using the interview research method and direct observation to the Medan City BPS office.
\end{abstract}

Keywords: BPS (Badan Pusat Statistik), PMTB, Survei, User, Web

\begin{abstract}
Abstrak: Susenas merupakan salah satu sumber data sosial ekonomi rumah tangga yang penting diindonesia. Susenas telah menjadi rujukan utama untuk memenuhi kebutuhan pemerintah dalam mengimplementasikan pembangunan nasional agar sejalan dengan Rencana Pembangunan Jangka Menengah Nasional (RPJMN), sembilan agenda prioritas atau nawacita dan tujuan Pembangunan Berkelanjutan. Survei adalah metode pengumpulan data dengan memberikan pertanyaan - pertanyaan kepada responden. survei merupakan cara terbaik dalam mendapatkan sebuah informasi yang benar dan dapat dipertanggungjawabkan hasilnya. Dalam proses pengumpulan data survei PMTB yang dilakukan oleh petugas mitra masih menerapkan sistem manual yang mana petugas mitra datang ke perusahaan/usaha membawah formulir pengisian data pendapatan dan pengeluaran perusahaan, dan selanjutnya mitra kembali menulis ke buku besar untuk dapat di analisa oleh petugas Neraca, penulis bermaksud membuat suatu sistem berbasis web yang dipandang dapat memberikan solusi yang efektif serta dapat dijadikan sebagai alat pendataan PMTB dengan menggunakan metode penelitian wawancara dan observasi langsung ke kantor BPS Kota Medan.
\end{abstract}

Kata kunci: BPS (Badan Pusat Statistik), PMTB, Survei, User, Web 
Vol. 1 No. 1, Maret 2021, hlm. 55 - 64

DOI: $\operatorname{xxxxxxxxxxxxxxxxx}$

Available online at http:// jurnal.stmikroyal.ac.id/index.php/j-com

\section{PENDAHULUAN}

Perkembangan ilmu pengetahuan dan teknologi yang sangat pesat dapat mempengaruhi kehidupan manusia. Adanya perkembangan teknologi dan era globalisasi yang tengah bergulir saat ini, Menjadikan kebutuhan informasi untuk sebuah data sangatlah penting. Data yang valid merupakan syarat utama sebuah informasi tersebut dapat dikatakan benar dan bisa dipertanggungjawabkan keasliannya. Data yang invalid akan mengakibatkan kekacauan dalam sebuah infomasi yang akan disajikan. Pengumpulan informasi dapat dilakukan dengan banyak cara, salah satunya dengan melakukan survei. Survei adalah metode pengumpulan data dengan memberikan pertanyaan - pertanyaan kepada responden. survei merupakan cara terbaik dalam mendapatkan sebuah informasi yang benar dan dapat dipertanggungjawabkan hasilnya.

Suatu sistem yang kurang mendapatkan informasi akan menjadi luruh,kerdil dan akhirnya berakhir. Jadi informasi itu sangat penting sekali artinya bagi suatu sistem sehingga suatu informasi adalah data yang diolah menjadi bentuk yang lebih berguna dan lebih berarti bagi yang menerimanya [1].

Badan Pusat Statistik adalah salah satu instansi pemerintah yang melayani masyarakat dalam menyediakan informasi sebuah data statistik yang akurat dan terpecaya. Sebelumnya, BPS merupakan Biro Pusat Statistik, yang dibentuk berdasarkan UU Nomor 6 Tahun 1960 tentang Sensus dan UU Nomor 7 Tahun 1960 tentang Statistik.

Dalam proses pengumpulan data survei PMTB yang dilakukan oleh petugas mitra masih menerapkan sistem manual yang mana petugas mitra datang ke perusahaan/usaha membawah formulir pengisian data pendapatan dan pengeluaran perusahaan, dan selanjutnya mitra kembali menulis ke buku besar untuk dapat di analisa oleh petugas Neraca. Namun penulis melihat permasalahan yang sering terjadi adalah pihak neraca selalu kehilangan buku dokumen, akibat terlalu banyaknya buku-buku yang harus di analisa dan di entri menjadi faktor sering terjadinya penumpukan dan kehilangan dokumen. Hal ini membuat pekerjaan menjadi lama, dan perlu dilakukan pensurveian kembali. Masalah ini dapat diatasi apabila pihak mitra memiliki sistem Penyusunan Disagregasi PMTB berbasis web yang dapat menyimpan hasil survei kedalam sistem.

Tujuan dari penelitian ini adalah untuk dapat mengatasi apabila pihak mitra dalam menyimpan hasil survei kedalam sebuah sistem. Sistem yang dibuat adalah sebuah aplikasi berbasis web, sehingga bisa diakses dimanapun dan kapanpun dengan adanya koneksi internet. Website merupakan keseluruhan halaman-halaman web yang terdapat dari sebuah domain yang mengandung informasi [2].

\section{METODE}

Tahapan atau cara-cara yang penulis lakukan selama dalam pengumpulan data yaitu wawancara dan observasi lapangan, dimana penulis melakukan wawancara terhadap kepala seksi/kepala bidang yang bersangkutan dalam Survei Penyusunan Disagregasi Pembentukan Modal Tetap Bruto (PMTB) di Kota Medan. Dan penulis juga melakukan pengamatan fisik/observasi dengan melihat dokumen hasil survei 
Vol. 1 No. 1, Maret 2021, hlm. 55 - 64

DOI: $\operatorname{xxxxxxxxxxxxxxxxx}$

Available online at http:// jurnal.stmikroyal.ac.id/index.php/j-com

lapangan yang dilakukan oleh petugas Mitra Badan Pusat Statistik dalam Survei Penyusunan Disagregasi Pembentukan Modal Tetap Bruto (PMTB)di Kota Medan.

Wawancara merupakan bentuk pengumpulan data yang paling sering digunakan dalam penelitian kualitatif. Wawancara pada penelitian kualitatif merupakan pembicaraan yang mempunyai tujuan dan didahului beberapa pertanyaan informal [3].

Dalam pengumpulan referensi, penulis meminjam beberapa buku yang bersangkutan di perpustakaan Universitas Pembangunan Panca Budi Kota medan, dan dari beberapa jurnal yang bersangkutan. Adapun hasil dari analisa proses terhadap sistem yang berjalan, maka penulis menggambarkan dalam Data Flowmap dapat dilihat pada gambar 1 :

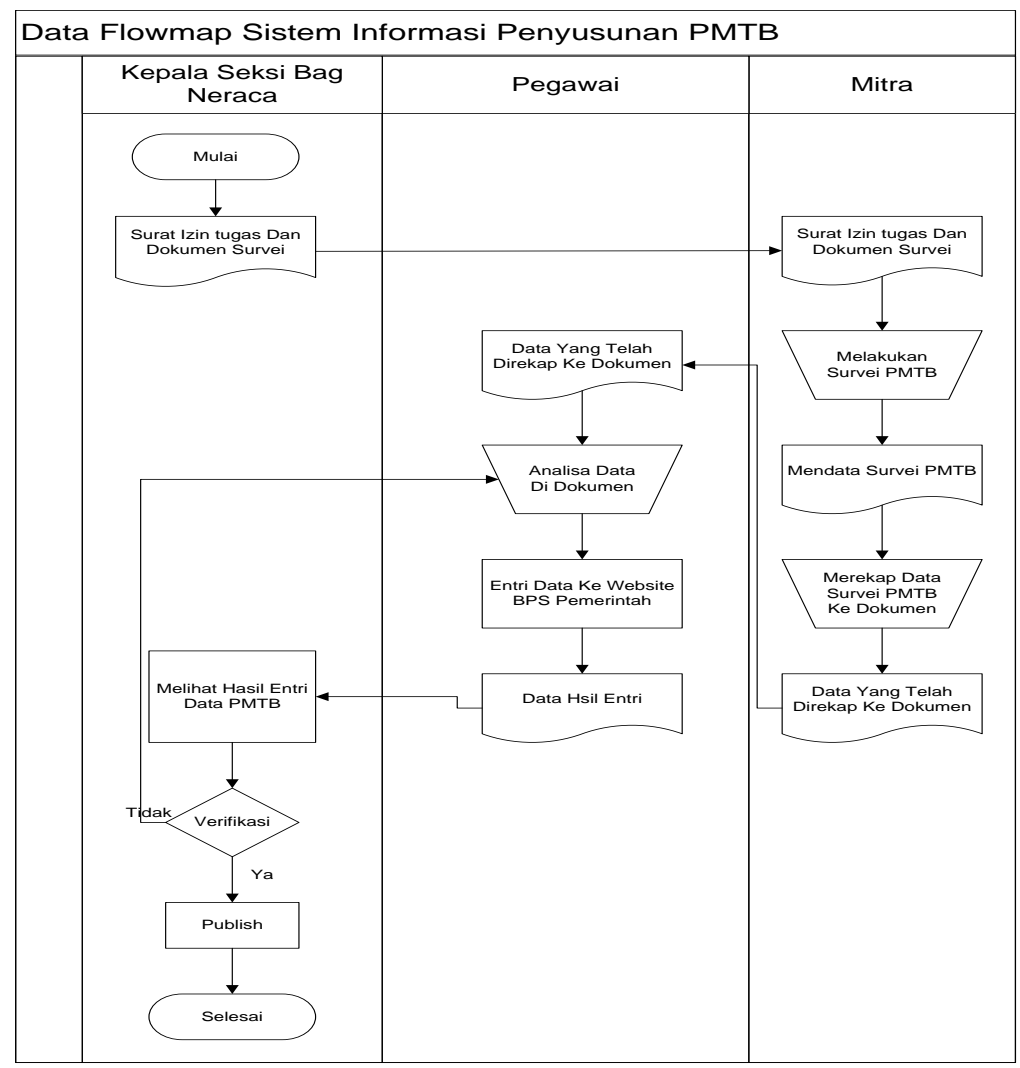

Gambar 1. Tampilan Proses Data Flowmap Pada BPS Kota Medan

Untuk mengembangkan sebuah sistem diatas, penulis menggunakan pemodelan UML. Uml merupakan metodologi dalam mengembangkan sistem berorientasi objek dan juga merupakan alat untuk mendukung pengembangan system [4].

Adapun gambar perancangan use case diagram sistem informasi media penyimpanan yang dapat menyimpan data-data hasil survei pada Kantor Badan Pusat Statistik Kota Medan dapat dilihat dari gambar 2 dibawah ini : 
Vol. 1 No. 1, Maret 2021, hlm. 55 - 64

DOI: $\mathrm{xxxxxxxxxxxxxxxxx}$

Available online at http:// jurnal.stmikroyal.ac.id/index.php/j-com

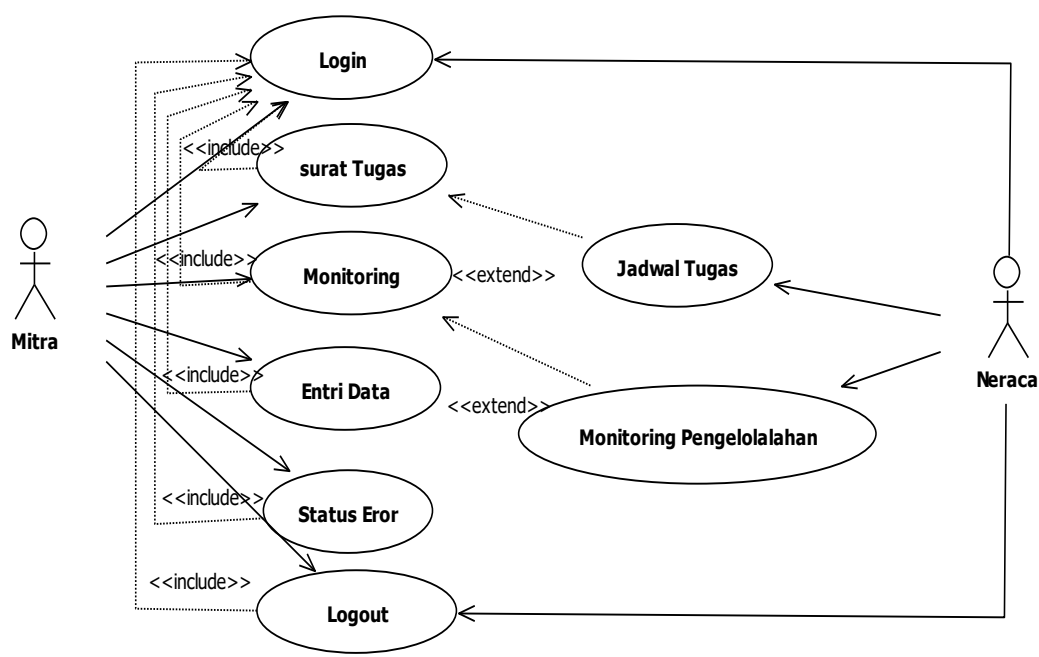

Gambar 2. Use Case Sistem Informasi Entri data Survei PMTB Pada Kantor BPS Kota Medan

\section{Activity Diagram}

Diagram ini adalah tipe khusus dari diagram state yang memperlihatkan aliran dari suatu aktifitas ke aktifitas lainnya dari suatu sistem [5].

Pada activity diagram login menggambarkan rangkaian aktivitas login yang dilakukan oleh pegawai neraca dan petugas mitra, yang selanjutnya akan mengarah pada halaman utama terlihat pada gambar 3 berikut :

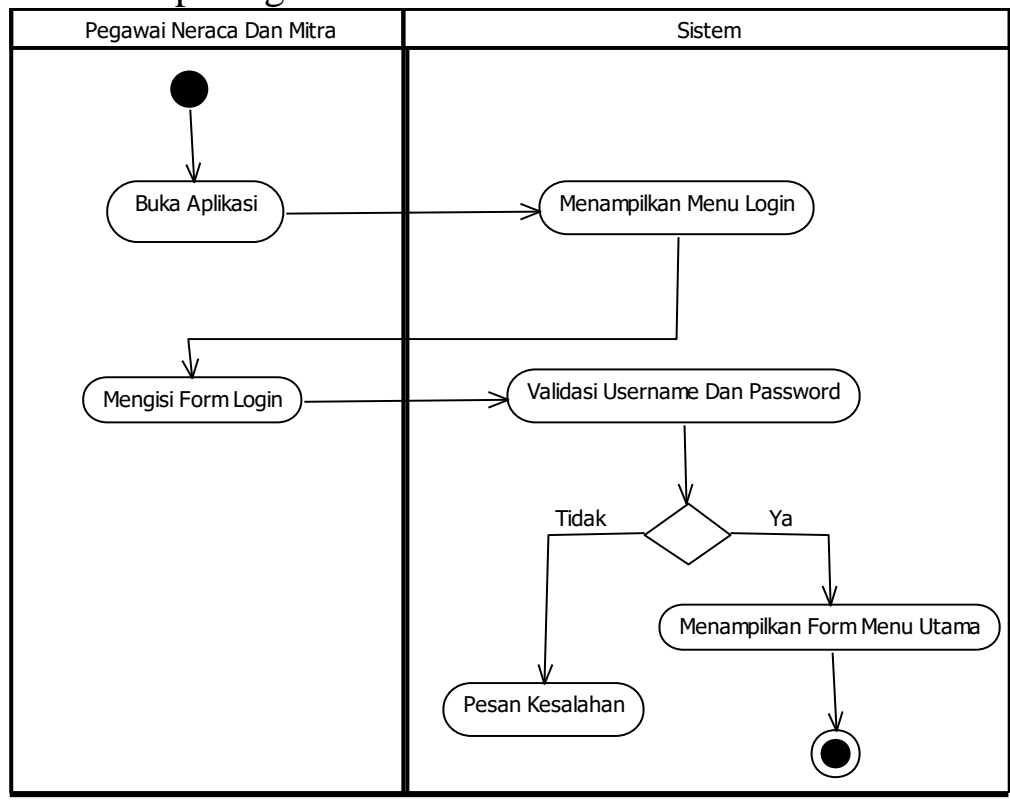

Gambar 3. Activity Diagram Login

Aktivitas mitra untuk melihat jadwal data tugas mitra pada sistem terlihat pada gambar 4 berikut : 
Vol. 1 No. 1, Maret 2021, hlm. 55 - 64

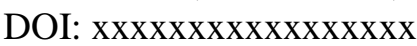

Available online at http:// jurnal.stmikroyal.ac.id/index.php/j-com

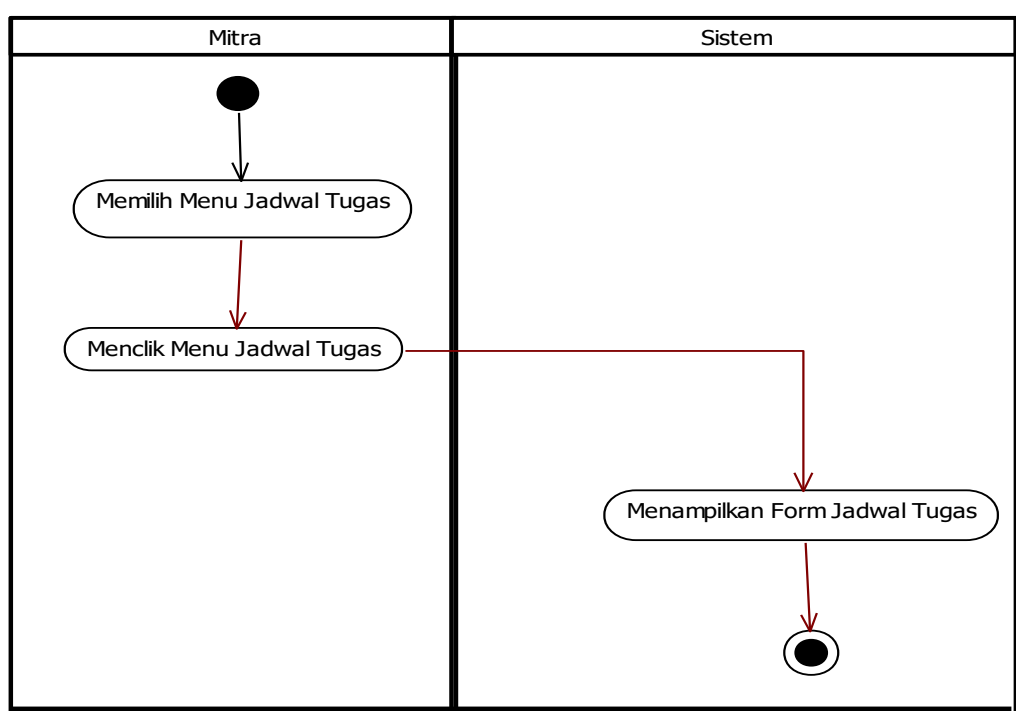

Gambar 4. Activity Jadwal Tugas Mitra

Aktivitas neraca untuk melakukan olah data tugas mitra pada sistem terlihat pada gambar 5 berikut :

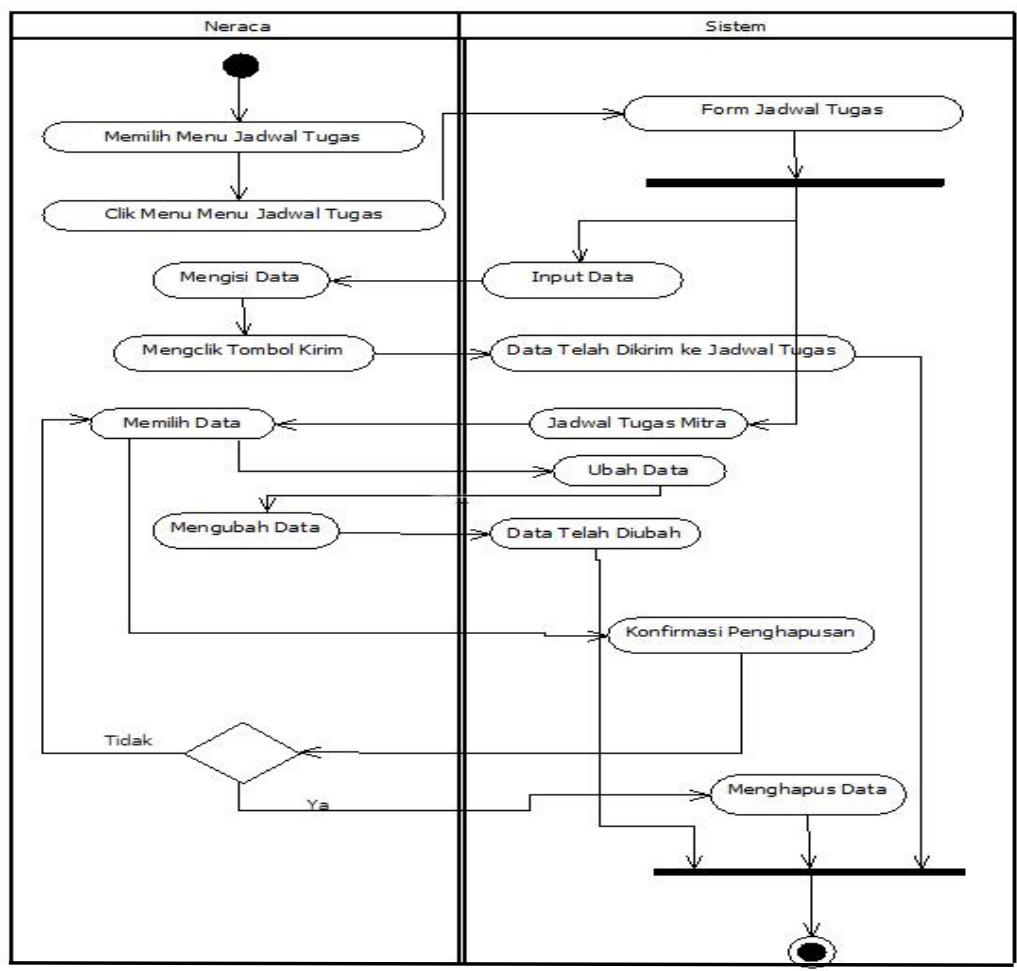

Gambar 5. Activity Jadwal Tugas Neraca

Aktivitas untuk melakukan entri data pada sistem yang di lakukan oleh pihak mitra dapat terlihat pada gambar 6 berikut : 
Vol. 1 No. 1, Maret 2021, hlm. 55 - 64

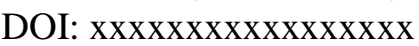

Available online at http:// jurnal.stmikroyal.ac.id/index.php/j-com

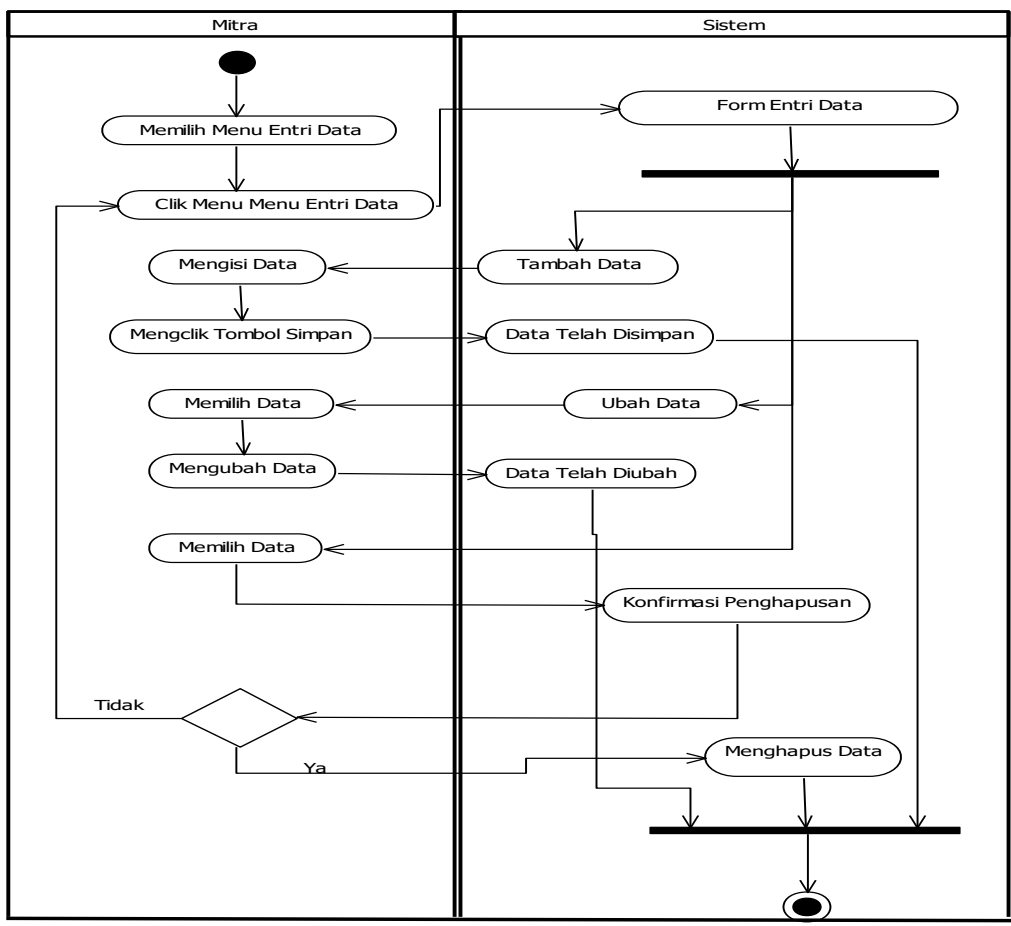

Gambar 6. Activity Entri Data Mitra

Aktivitas mitra untuk melihat data monitoring yang sudah terproses pada sistem terlihat pada gambar 7 berikut :

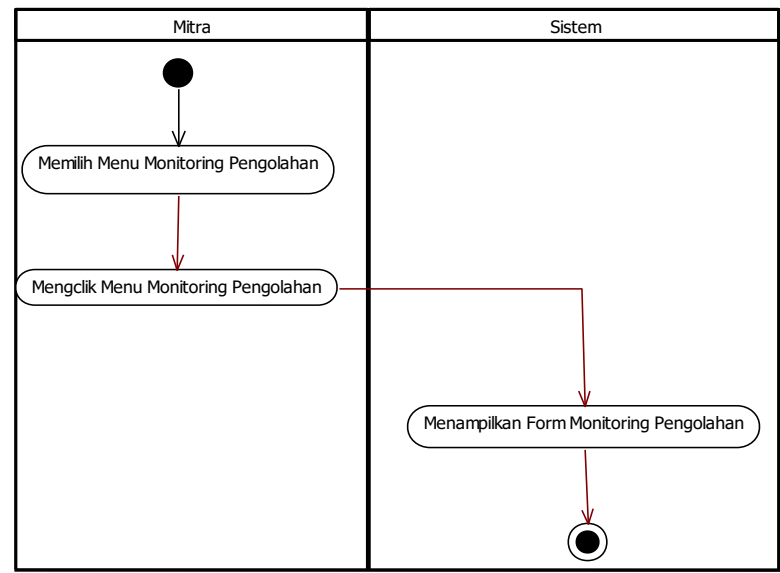

Gambar 7. Activity Monitoring Mitra

\section{HASIL DAN PEMBAHASAN}

Hasil tampilan halaman menu utama merupakan halaman login ke website yang lakukan oleh pihak Mitra dan Neraca dapat dilihat pada gambar 8 berikut : 
Vol. 1 No. 1, Maret 2021, hlm. 55 - 64

DOI: $\operatorname{xxxxxxxxxxxxxxxxx}$

Available online at http:// jurnal.stmikroyal.ac.id/index.php/j-com

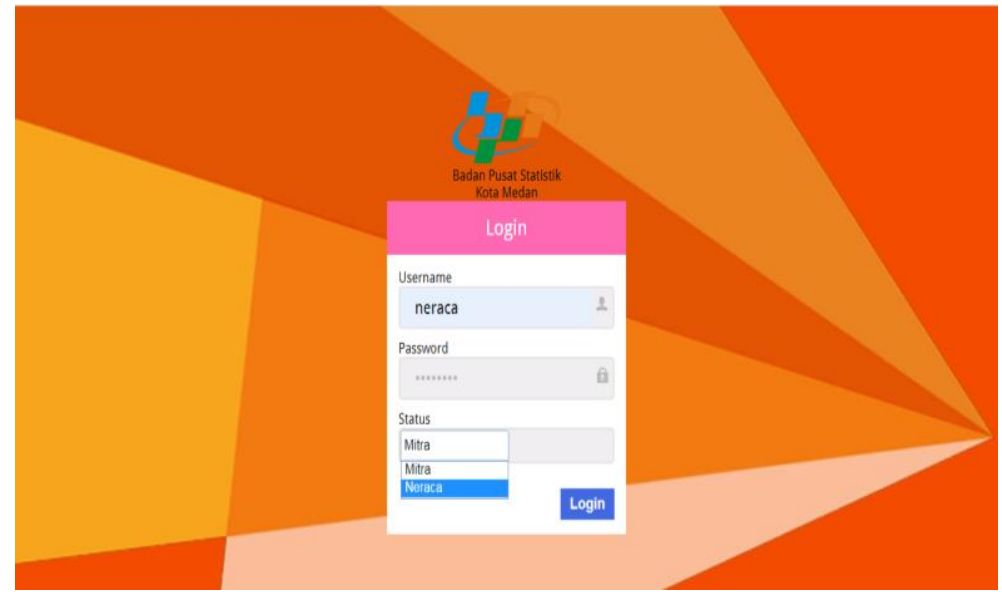

Gambar 8. Hasil Menu Login Mitra.

Hasil tampilan halaman Menu Home merupakan halaman kedua dari Setelah login kemudian setelah itu akan menampilkan menu home. Dalam tampilan home terdapat menu pilihan untuk menu home mitra terdapat seperti menu jadwal tugas, menu monitoring, menu entri data, dan menu status erorr. Sedangkan di halaman menu home Neraca hanya akan menampilkan menu jadwal tugas, menu monitoring. Ini dikarenakan sesuai dengan kebutuhan dari setiap penggunaan website dapat dilihat pada gambar 9 dan 10 berikut :

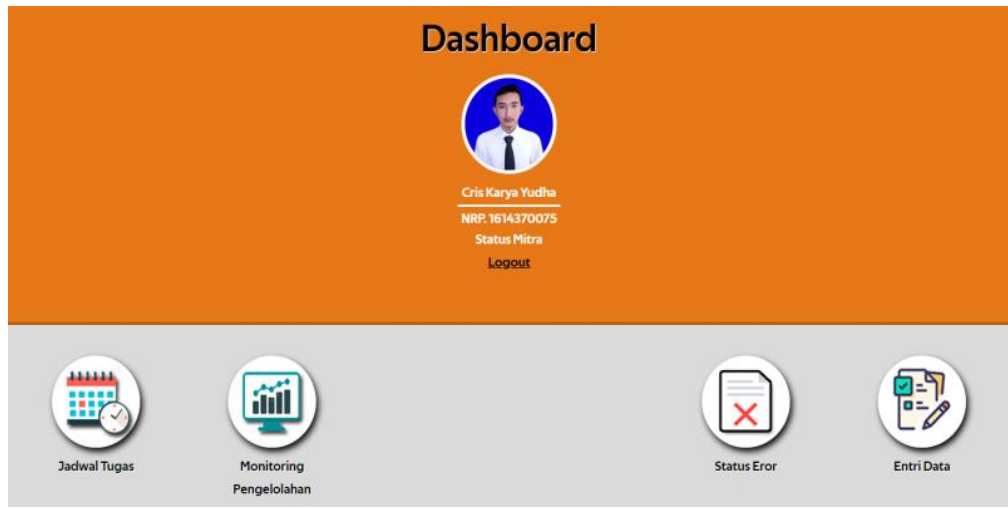

Gambar 9. Hasil Menu Home Mitra

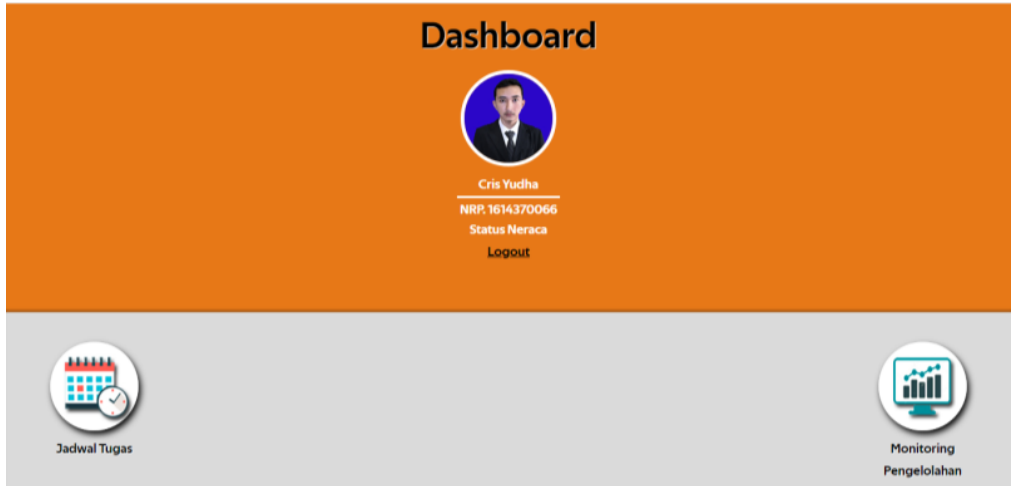

Gambar 10. Hasil Menu Home Neraca 
Vol. 1 No. 1, Maret 2021, hlm. 55 - 64

DOI: $\mathrm{xxxxxxxxxxxxxxxxx}$

Available online at http:// jurnal.stmikroyal.ac.id/index.php/j-com

Hasil tampilan Halaman Menu Jadwal Tugas Mitra merupakan halaman yang menampilkan jadwal - jadwal tugas mitra yang diberikan oleh pegawai neraca untuk mitra. Selanjutnya mitra melihat jadwal tugas dan memilih wilayah yang sesuai, jika ingin di ambil maka tinggal menklik tombol ambil maka akan secara automatis akan menampilkan surat tugas, dan jika tidak sesuai maka bisa di tolak, maka jadwal tersebut akan kembali ke status belum terpilih. Dapat dilihat pada gambar 11 berikut :

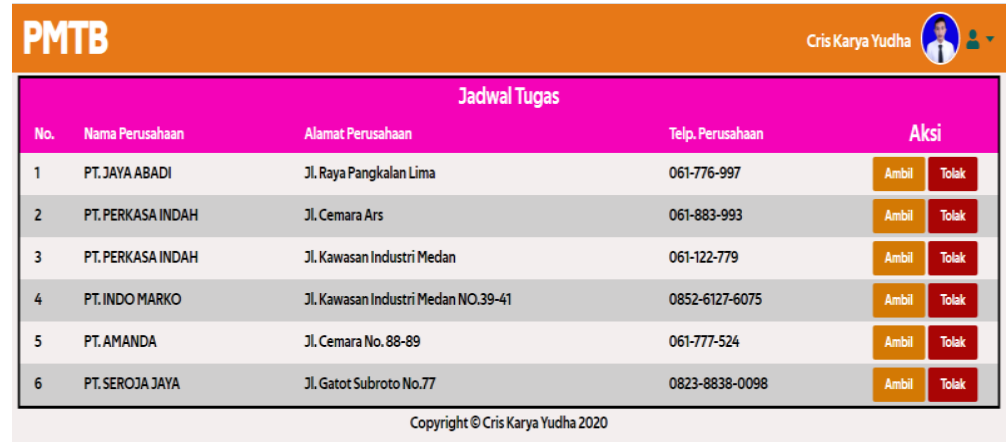

Gambar 11. Hasil Menu Jadwal Tugas Mitra

Hasil tampilan Halaman Menu Jadwal Tugas Neraca merupakan halaman yang menampilkan input surat tugas untuk mitra dan menampilkan daftar nama nama petugas mitra yang telah mendapatkan surat tugas. Pegawai neraca yang bertanggung jawab atas penjadwalan untuk petugas mitra. Neraca menentukan nama petugas mitra dan id mitra. Selanjutnya neraca menentukan nama perusahaan dan alaman yang belum di survei. Dapat dilihat pada gambar 12 berikut :

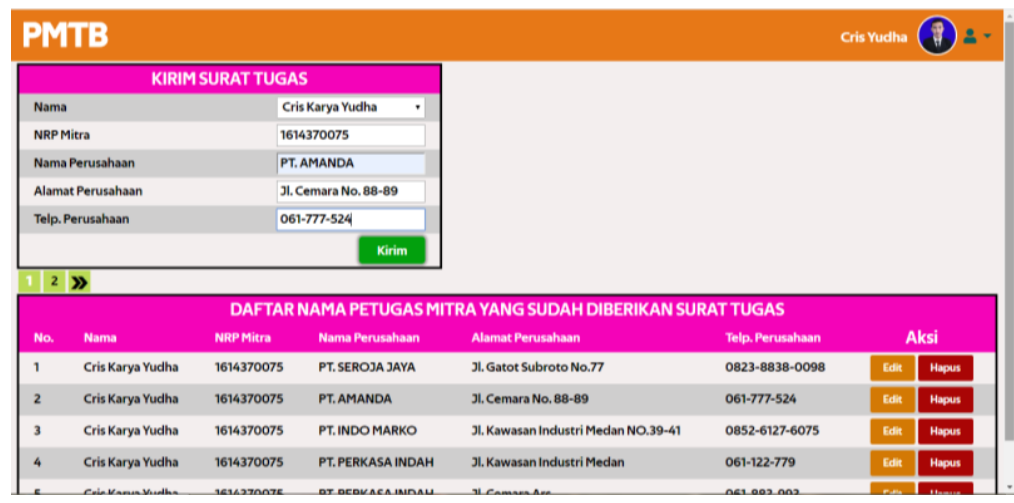

Gambar 12. Hasil Menu Jadwal Tugas Neraca

Hasil tampilan Halaman Menu Entri Data merupakan halaman yang menampilkan penginputan data hasil survei PMTB yang dilakukan oleh petugas mitra. Pertama mitra melakukan survei lapangan setelah selesai melakukan survei maka selanjutnya mitra menginput hasil survei kedalam sistem, yang selanjutnyaakan di kirim ke pegawai neraca untuk dianalisa. Dapat dilihat pada gambar 13 berikut : 
Vol. 1 No. 1, Maret 2021, hlm. 55 - 64

DOI: $\mathrm{xxxxxxxxxxxxxxxxx}$

Available online at http:// jurnal.stmikroyal.ac.id/index.php/j-com

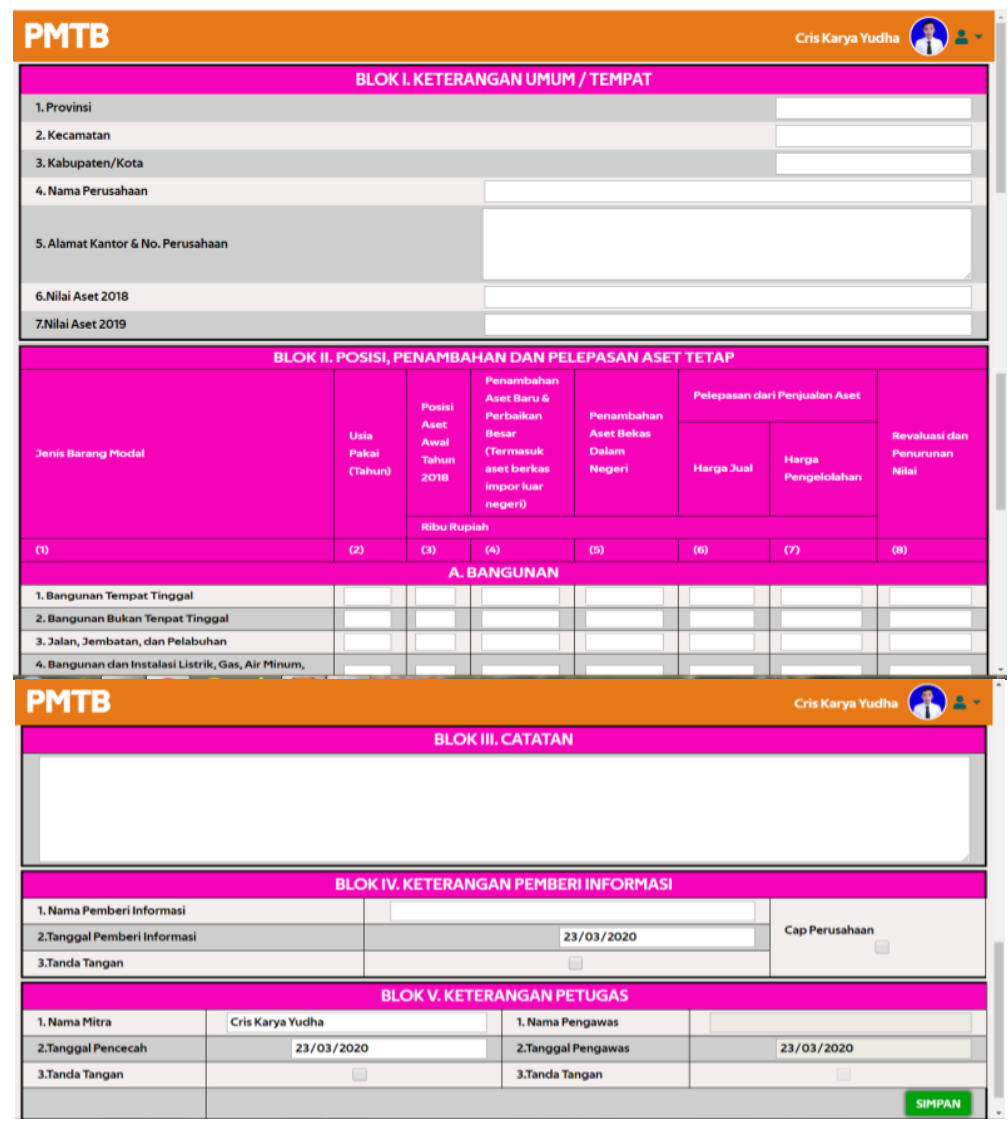

Gambar 13. Hasil Menu Entri Data

Halaman Menu Monitoring Mitra merupakan halaman yang menampilkan penginputan data hasil survei PMTB yang dilakukan oleh petugas mitra setelah itu pegawai neraca menganalisa jika sudah selesai di analisa maka akan langsung di input ke dalam website nasional BPS, hasil survei yang sudah di analisa maka akan memberikan tampilan status clean, apabila belum akan akan menampilkan status belum, sehingga ini yang dapat membedakan mana yang sudah di entri, dan mana yang belum di entri. Dan apabila status belum dientri maka hasil survei masih bisa di edit. Tetapi jika sudah clean maka status edit itu akan hilang secara automatis. Dapat dilihat pada gambar 14 berikut :

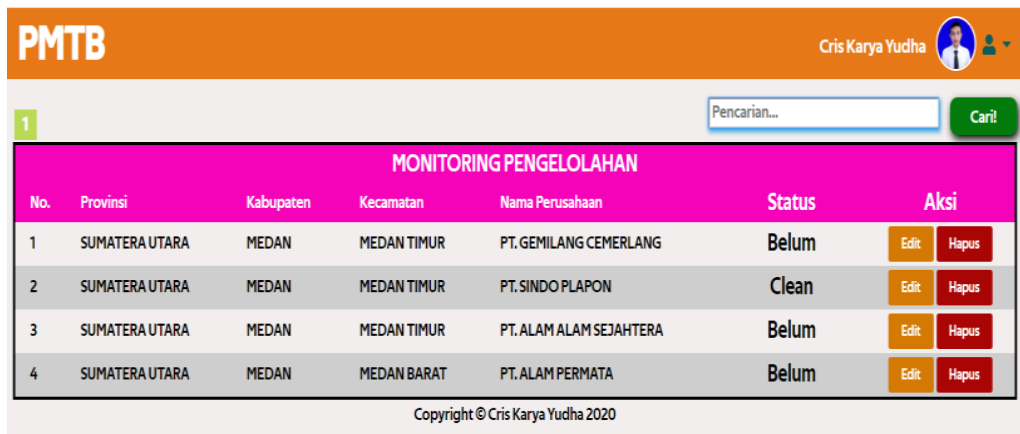

Gambar 14. Hasil Menu Monitoring Mitra 
Vol. 1 No. 1, Maret 2021, hlm. 55 - 64

DOI: $\mathrm{xxxxxxxxxxxxxxxxx}$

Available online at http:// jurnal.stmikroyal.ac.id/index.php/j-com

\section{SIMPULAN}

Dari Hasil Kesimpulan Rancang Bangun Sistem Informasi Survei Penyusunan Disagregasi Pembentukan Modal Tetap Bruto (Pmtb) Berbasis Web ini adalah suatu proses pengumpulan data perusahaan, hal ini dilakukan agar mempermudah dalam pemberian modal terhadap seseorang yang ingin memulai usahanya. Adanya Sistem Informasi Survei Penyusunan Disagregasi Pembentukan Modal Tetap Bruto (Pmtb) Berbasis Web tersebut dapat mempercepat dalam proses pengumpulan data yang dilakukan oleh mitra dan memudahkan penyajian informasi. Penggunaan software PHP dapat memudahkan user dalam mengakses website dan MySql sebagai database server yang memudahkan untuk pencarian suatu data.

\section{DAFTAR PUSTAKA}

[1] V. Tasril, K. Khairul, and F. Wibowo, "Aplikasi Sistem Informasi Untuk Menentukan Kualitas Beras Berbasis Android Pada Kelompok Tani Jaya Makmur Desa Benyumas," J. Inform., vol. 7, no. 3, pp. 133-142, 2019, doi: 10.36987/informatika.v7i3.1384.

[2] Y. Sen Sun, B. Qiu, and Q. S. Li, "The research of negative ion test method for fabric," Adv. Mater. Res., vol. 756-759, no. 1, pp. 138-140, 2013, doi: 10.4028/www.scientific.net/AMR.756-759.138.

[3] I. N. Rachmawati, "Pengumpulan Data Dalam Penelitian Kualitatif: Wawancara," J. Keperawatan Indones., vol. 11, no. 1, pp. 35-40, 2007, doi: 10.7454/jki.v11i1.184.

[4] V. Tasril, R. F. Wijaya, and R. Widya, "Aplikasi Pintar Belajar Bimbingan Dan Konseling Untuk Siswa Sma Berbasis Macromedia Flash,” J. Inf. Komput. Log., pp. 2019, [Online]. Available: http://ojs.logika.ac.id/index.php/jikl/article/download/45/53.

[5] P. Sulistyorini, "Pemodelan Visual dengan Menggunakan UML dan Rational Rose," J. Teknol. Inf. Din. Vol., vol. XIV, no. 1, pp. 23-29, 2009. 